\title{
O novo romance histórico brasileiro ${ }^{1}$
}

Carlos Alexandre B aumgarten² 
Todo romance, como produto de um ato de escrita é sempre histórico, porquanto revelador de, pelo menos, um tempo a que poderíamos chamar de tempo da escrita ou da produção do texto. Contudo, tal definição, por mais verdadeira que possa ser, não serve para o que comumente nomeamos de romance histórico no plano dos estudos literários. Nesse âmbito, romance histórico corresponde àquelas experiências que têm por objetivo explícito a intenção de promover uma apropriação de fatos históricos definidores de uma fase da $\mathrm{H}$ istória de determinada comunidade humana. Assim entendido, o romance histórico surgiu no curso do século XIX e tem sua origem vinculada à produção literária de Walter Scott. $M$ ais do que isso, surgindo ainda na vigência do Romantismo, época em que se definiam as diferentes nacionalidades européias e americanas, o romance histórico desempenhou importante papel na construção das nacionalidades/identidades que almejavam se afirmar pela diferença. No caso da literatura brasileira não foi diferente, basta para tanto que se analise a produção romanesca de J osé de Alencar. Ao conceber As mi nas de prata (1862) e A guerra dos mascates (1873), o romântico brasileiro não só apontou um dos caminhos a serem observados na construção da nova nação que desejava se afirmar - atestar que a mesma possuía uma história própria e que, portanto, era distinta da antiga Metrópole como também ancorou a literatura produzida no País numa das vertentes - a do romance histórico - que há muito vinha sendo cultivada pelas nações européias.

O romance histórico, tal como foi concebido na sua origem, apresenta, entre outras, as seguintes marcas que Ihe são essenciais, como bem aponta L ukács ${ }^{3}$ em sua obra sobre o assunto: 
a - traçam grandes painéis históricos, abarcando determinada época e um conjunto de acontecimentos;

b - a exemplo dos procedimentos típicos da escrita da História, organizam-se em observância a uma temporalidade cronológica dos acontecimentos narrados;

c - valem-se de personagens fictícias, puramente inventadas, na análise que empreendem dos acontecimentos históricos;

d - as personalidades históricas, quando presentes, são apenas citadas ou integram o pano de fundo das narrativas;

e - os dados e detalhes históricos são utilizados com o intuito de conferir veracidade à narrativa, aspecto que torna a História incontestável;

f - o narrador se faz presente, em geral, na terceira pessoa do discurso, numa simulação de distanciamento e imparcialidade, procedimento herdado igualmente do discurso da História.

No século XX, contudo, inúmeras são as transformações por que passa o romance histórico, que tem sua escrita redimensionada em vários aspectos. A crítica e a historiografia literárias ${ }^{4}$ tendem a localizar a origem desse processo na obra 0 reino deste mundo (1949), do cubano Alejo Carpentier, uma vez que a mesma já apresenta grande parte dos elementos que caracterizam o chamado novo romance histórico, especialmente aquele produzido a partir dos anos 70 do século $X X$.

No caso brasileiro, podemos afirmar que, após os anos 70, assistimos ao aparecimento de um grande número de romances voltado para a recuperação e a escrita da história nacional, que é revisitada em seus diferentes momentos. A leitura do conjunto dessa produção revela, pelo menos, a existência de dois caminhos que, preferencialmente, têm sido observados pelos autores: de um lado, situam-se as narrativas que focalizam acontecimentos integrantes da história oficial e, por vezes, definidores da própria constituição física das fronteiras brasileiras; de outro, aquelas que promovem a revisão do percurso desenvolvido pela história literária nacional. No primeiro grupo, encontram-se obras como A prole do corvo (1978) , de Luiz Antonio de Assis B rasil, A estranha nação de Rafael Mendes (1983), de M oacyr Scliar, A cidade dos padres (1986), de Deonísio da Silva, Agosto (1990), de Rubem Fonseca, entre tantas outras. No segundo, Em liberdade (1981), de Silviano Santiago, Cães da Província (1987), de Luiz Antonio de Assis Brasil, Boca do Inferno ( 1990) e A última quimera (1995), ambos de Ana M iranda. Enquanto as primeiras, via de regra, têm como protagonistas personalidades da história oficial

\footnotetext{
LUKÁCS, G eorg. La novela histórica. México: Ediciones Era, 1966.

V., a propósito: MENTON, Seymor. La nueva novela histórica de la América latina. 1979-1992. México: Fondo de Cultura E conómica, 1993. Ver ainda: BALDERST ON, Daniel (org.). The historical novel in Latin American. New Orleans: Ediciones Hispamérica, 1986.
} 
brasileira, as últimas organizam-se em torno da trajetória pessoal de nomes da história literária nacional.

É , contudo, com Galvez, Imperador do Acre (1975), do amazonense Márcio Souza ${ }^{5}$, que, pioneiramente, o romance histórico brasileiro tem suas fronteiras redefinidas. Valendo-se do episódio da anexação do território do Acre pelo Brasil, na virada do século XIX, o autor constrói uma narrativa então inovadora, uma vez que afinada com o que de mais recente podia ser encontrado no âmbito do romance histórico latino-americano. M ais do que isso, a obra de $M$ árcio Souza transita pelos dois caminhos anteriormente referidos, pois, simultaneamente, focaliza fato da história do País e desenvolve ampla reflexão sobre o processo literário nacional.

O texto de Márcio Souza apresenta-se estruturado em quatro partes: a primeira, sem título, demarcada apenas pelas datas novembro de 1897 a novembro de 1898; a segunda, intitulada Em pleno rio Amazonas; a terceira, compreendida entre março e junho de 1899; a última, de título O império do Acre, ocupa, no plano temporal, de julho a dezembro de 1899. Antes do início da narrativa propriamente dita, há uma espécie de advertência ao leitor em que se lê o que segue:

A vida e a prodigiosa aventura de Dom L uiz G alvez R odrigues de Aria nas fabuIosas capitais amazônicas e a burlesca conquista do Território Acreano com perfeito e justo equilíbrio de raciocínio para a delícia dos leitores. ${ }^{6}$

A leitura do romance revela que o mesmo cumpre integralmente a advertência, pois são narradas as aventuras de Luiz Galvez e, ao mesmo tempo, como é próprio do gênero burlesco, a conquista e anexação do Acre, episódio da constituição das fronteiras brasileiras e, portanto, um assunto sério, é narrada em estilo escrachado e cômico, estabelecendo-se aí a característica essencial do burlesco, que é a discrepância entre o estilo e o assunto. Além disso, reforçando o tom burlesco que marca o texto, há inúmeras passagens em que temas importantes são tratados com fingida dignidade.

Se o burlesco configura-se plenamente, a caracterização da narrativa como folhetim, presente na página de rosto, não se confirma, pois o suspense, sua marca essencial, é, desde logo, rompido com a afirmação inicial do narrador: "Esta é uma história de aventuras onde o herói, no fim, morre na cama de velhice" (p. 15). Para além da ruptura com o modelo do folhetim, a afirmação do narrador rompe

5 Márcio Souza é autor de uma obra romanesca considerável, em que se destacam, além de Galvez, I mperador do Acre, A resistível ascensão do Boto Tucuxi (1982); Mad Maria (1983); A ordem do dia (1983); A condolência (1984); O brasileiro voador (1986) e Lealdade (1997), entre outros.

6 SOUZA, Márcio. Galvez, Imperador do Acre. Rio de J aneiro: Ed. Brasília, 1977. p. 3. Todas as citações do texto de Márcio Souza pertencem a essa edição. 
igualmente com a linearidade temporal típica das narrativas históricas tradicionais. O processo de desvelamento dos procedimentos composicionais próprios do folhetim tem continuidade, no desenrolar do texto, com as constantes intromissões do narrador antecipando o desfecho dos acontecimentos.

O romance tem como protagonista Luiz G alvez R odrigues de Aria, aventureiro espanhol envolvido no movimento de ocupação das terras à época pertencentes à B olívia, e organiza-se em torno de dois narradores, ambos em primeira pessoa: um que se coloca na pele de editor, e outro que é o próprio G alvez que, tal como ocorre no plano dos relatos autobiográficos, narra suas memórias. O narrador editor não apenas introduz e conclui a narrativa, como freqüentemente interfere no relato do narrador personagem, corrigindo-o mesmo em suas memórias, num evidente processo de desmistificação da verdade que reivindica para si duas modalidades discursivas: a da História e a da autobiografia. Nesse sentido, ao narrar episódio em que bravamente obtivera certo documento, Galvez é interrompido pelo narrador editor, que afirma:

Perdão, leitores! Neste momento sou obrigado a intervir, coisa que farei a cada momento em que o nosso herói faltar com a verdade dos fatos. É claro que ele conseguiu o documento. Mas da maneira mais prosaica do mundo. (p. 45)

O mesmo narrador editor é o responsável pela natureza metaficcional que a narrativa assume em todo seu desenvolvimento, pois não são raros os momentos em que se manifesta a respeito de sua estrutura e organização. Assim, afirma ele, inicialmente, que

Esta é uma história de aventuras onde o herói, no fim, morre na cama de velhice. E quanto ao estilo o leitor há de dizer que finalmente o Amazonas chegou em 1922. Não importa, não se faz mais histórias de aventuras como antigamente. (p. 15)

Ao mesmo tempo em que caracteriza a narrativa como história de aventuras, o narrador editor dá início à reflexão sobre o processo literário nacional, através de referência explícita ao movimento modernista, que tem, na Semana de Arte M oderna de São Paulo, de 1922, seu marco instaurador. Tal reflexão tem continuidade no parágrafo seguinte, quando diz que os manuscritos das memórias de Galvez foram encontrados num sebo em Paris e que, a exemplo do que fizera J osé de Alencar com o livro Guerra dos mascates, resolvera organizá-los e publicá-los. Trata-se, evidentemente, de um discurso através do qual parodia-se procedimento composicional que, utilizado insistentemente no curso da narrativa brasileira 
do século XIX, tornou-se um verdadeiro clichê. O discurso paródico, assim utilizado, reveste-se de uma dupla orientação: de um lado, ilumina a tradição literária, revigorando-a; de outro, renova a prática discursiva exaustivamente explorada no campo da produção romanesca, ao conferir-lhe significado novo.

O diálogo com a história literária brasileira efetiva-se com igual força no que tange às relações com o gênero memorialístico. Nesse sentido, estabelece vínculos com Memórias de um sargento de milícias (1853), de Manuel Antônio de Almeida, via tradição da novela picaresca: assim como Leonardo, protagonista do romance de M. A. de Almeida, Galvez caracteriza-se como um pícaro, à medida que, ao servir de elemento de ligação entre os diferentes capítulos da narrativa, garante sua unidade. Clara igualmente é a relação que estabelece com Memórias senti mentais de J oão Miramar (1924), do modernista Oswald de Andrade, especialmente no que diz respeito à estruturação do romance, constituído de pequenos fragmentos narrativos, e também no que se refere à farta utilização do discurso paródico e ao diálogo permanente com a tradição cultural brasileira.

A natureza intertextual de Galvez, I mperador do Acre, além do já referido, manifesta-se também através do recurso da citatividade. Nessa medida, os capítulos Commemorazzi one Verdiana, Ainda Giuseppe, Radamés, Luar sobre o Nilo, A Cripta, Dueto Final e Dueto Bufo ( p. 54-58) constituem uma seqüência que se organiza a partir da incorporação e citação literal de passagens da ópera Aída, de Verdi. Em outros momentos, o romance se apropria de escritos de autoria de Cervantes, Calderón de La B arca e Lope de Vega e dá continuidade ao diálogo com a tradição ibérica, antes iniciado através da vinculação à novela picaresca.

Além desses dois narradores, a instância da narração é, por vezes, ocupada por outras personagens, como no capítulo intitulado Pintura rupestre ( p. 78), em que Sir Henry, cientista britânico em expedição na Amazônia, assume o relato e desenvolve toda uma teoria a respeito do Teatro Amazonas, de M anaus. Em outros momentos, faz-se presente recurso típico do texto teatral, à medida que há diálogos autônomos, que se realizam sem qualquer interferência do narrador, como é o caso dos capítulos Diálogos do 3o Mundo I (p. 169) e Diálogos do 3o Mundo II (p. 161).

Outro aspecto marcante na narrativa de Márcio Souza é a forma irônica e carnavalizada por ela assumida, nos termos em que foi proposta por Mikhail B akhtin ${ }^{7}$. N essa perspectiva, Galvez, I mpera dor do Acre reveste-se de um caráter desmascarador, ao pôr a nu as mazelas da história política brasileira, sobretudo na sua truculência e instabilidade. $O$ mesmo destino têm as elites brasileiras, cuja falsa moralidade é objeto de um discurso permanentemente irônico. 
Além disso, o romance assume uma forma carnavalizada que se manifesta através de inúmeros índices, como, por exemplo, o da profanação presente nos episódios Liturgia e Novena, nos quais o herói envolve-se com uma freira e com ela mantém relações sexuais. A coroação bufa, principal ritual da carnavalesca, aparece vinculada ao episódio histórico da anexação do Acre, quando Galvez é coroado imperador. Verdadeiro herói bufo, G alvez toma conta de Puerto Alonso, posto situado na fronteira entre Brasil e Bolívia, que era guarnecido por aproximadamente uma dezena de soldados. No dia da coroação, ocorre uma grande orgia, regada a álcool, que promove a abolição de qualquer relação hierárquica entre os homens que dela participam, como se pode perceber na seguinte transcrição:

Quando a noite chegou, já ninguém se entendia e o álcool havia abolido as hierarquias. $O$ interior do Palácio Imperial era um ponto sensitivo onde corpos exultavam mudos e ocupados e as almas perdiam-se em êxtases e torrentes de calor. (p. 170)

Compreendido entre os capítulos Viva o Imperador do Acre (p. 146) e Minha deposi ção ( p. 171), o processo de entronização e derrubada de Galvez apresenta, além disso, outros elementos típicos do carnaval, como é o caso da cena montada para sua coroação. Acompanhado por um grupo de artistas franceses, em excursão pelo Brasil, Galvez, em plena selva amazônica, incumbe o coreógrafo e figurinista da companhia, então nomeado ministro da cultura, de montar um cenário, simulando a entrada de um grande palácio que, ao final da festa, aparece completamente destruído.

E m Galvez, o índice mais expressivo da carnavalesca é talvez aquele que diz respeito à utilização de registros discursivos da mais diversa origem. Assim, as personagens trocam cartas e telegramas entre si; G alvez, chefe das forças revolucionárias pelo Acre ind ependente, redige ordens de serviço, que constituem capítulos do romance, como o seguinte:

Ordem de serviço!

Do: Comandante G alvez.

Para: Intendente Chefe.

Prezado Senhor, venho por meio desta ordenar um remanejamento em nossas compras. Queira diminuir a munição em quatro caixotes de balas e adicionar duas caixas de vinho e vinte dúzias de cervejas.

Saudações revolucionárias.

Viva o Acre independente.

Galvez, Comandante-em-Chefe. (p. 115) 
Galvez, recém coroado imperador, redige e faz publicar decretos que, igualmente, constituem capítulos da narrativa; seus companheiros de aventura, nomeados para altos postos militares, fazem circular ordens do dia e despachos. Há, ainda, um intenso uso da linguagem jornalística, mediante a transcrição de notícias publicadas nas páginas de jornais. Assim como a história política brasileira e a ação de sua diplomacia são objeto de crítica ao longo da narrativa, o discurso dos movimentos de esquerda, notadamente em seus lugares-comuns, não passa impune. Exemplos típicos dessa circunstância são as duas atas (p. 40-41) em que o movimento revolucionário pela independência do Acre registra as reuniões preparatórias para a expedição.

Em síntese, esta breve leitura de Galvez, I mperador do Acre, mostra que o romance de Márcio Souza apresenta as seguintes marcas caracterizadoras:

a - consciência da impossibilidade de determinar, por meio do discurso/palavra, a incontestável verdade histórica;

b - concepção de que a H istória é imprevisível, opondo-se, conseqüentemente, àqueles que vêem na História um caráter cíclico; em verdade, desenvolve-se a idéia de que os mais surpreendentes e inesperados fatos podem ocorrer;

c - consciente distorção da história por meio de omissões, exageros e anacronismos, aspecto responsável pela ruptura da linearidade temporal característica do gênero;

d - utilização de personagens históricos como protagonistas das narrativas;

e - caráter metaficcional, ou o comentário do narrador sobre o processo de criação de seu próprio texto;

f - natureza intertextual, à medida que o romance é construído como um mosaico de citações; em outras palavras, o texto pode ser visto como a absorção e a transformação de um outro texto, obrigando a leitura da linguagem poética pelo menos como dupla;

g - caráter paródico com relação a outros textos que tenham abordado ou não os mesmos fatos da história;

h - forma dialógica, irônica e carnavalizada, nos termos em que foi proposta por Bakhtin em seus estudos sobre o discurso romanesco.

Este conjunto de inovações presentes em Galvez, Imperador do Acre, de Márcio Souza, sinaliza, em verdade, para o surgimento de um novo paradigma no plano da escrita do romance histórico brasileiro, que é também compartilhado pelas obras de Deonísio da Silva, L uiz Antonio de Assis B rasil, Ana M iranda, M oacyr Scliar e de tantos outros que têm se dedicado à revisão da história oficial brasileira pelo viés da ficção. 


\section{Referências Bibliográficas}

AGUIAR, F lávio et alii (orgs.). Gêneros de frontei ra. Cruzamentos entre o histórico e o literário. São Paulo: Xamã, 1997.

BRAIT, B eth (org.). Bakhti n, dialogi smo e construção do senti do. Campinas: Unicamp, 1997.

CHIAPPINI, Lígia \& AGUIAR, Flávio (orgs.). Literatura e história na América Latina. São Paulo: Edusp, 1993.

HUTCHEON, Linda. Uma teoria da paródia. Trad. Teresa Louro Pérez. Lisboa: E dições 70, 1989.

Poética do Pós-Moderni smo: história, teoria, ficção. Rio de J aneiro: I mago, 1991.

LEENHARDT, J acques \& PESAVENTO, Sandra J atahy (orgs.). Discurso histórico e narrativa literária. Campinas: Unicamp, 1998. 
